\title{
Inhibiting the cytoplasmic location of HMGB1 reverses cisplatin resistance in human cervical cancer cells
}

\author{
JIYI XIA ${ }^{1 *}$, XIAOLAN YU ${ }^{2 *}$, XUEQIN SONG $^{3},{\text { GANG } \mathrm{LI}^{4}, \text { XIGUANG MAO }}^{5}$ and YUJIAO ZHANG ${ }^{5}$ \\ ${ }^{1}$ School of Medical Information and Engineering, Southwest Medical University; ${ }^{2}$ Department of Obstetrics and Gynecology, \\ The Affiliated Traditional Chinese Medicine Hospital of Southwest Medical University; ${ }^{3}$ Experimental Medicine Center, \\ Departments of ${ }^{4}$ Pediatrics, and ${ }^{5}$ Obstetrics and Gynecology, The Affiliated Hospital of Southwest Medical University, \\ Luzhou, Sichuan 646000, P.R. China
}

Received October 19, 2015; Accepted October 31, 2016

DOI: $10.3892 / \mathrm{mmr} .2016 .6003$

\begin{abstract}
Cervical cancer is the fourth most common malignancy in women worldwide, and resistance to chemotherapy drugs is the biggest obstacle in the treatment of cervical cancers. In the present study, the molecular mechanisms underlying cisplatin resistance in human cervical cancer cells were investigated. When human cervical cancer cells were treated with $10 \mu \mathrm{g} / \mathrm{ml}$ of cisplatin for 24 and $48 \mathrm{~h}$, high mobility group box 1 (HMGB1) protein expression levels significantly increased in a time-dependent manner. Comparisons between cisplatin-sensitive HeLa cells and cisplatin-resistant HeLa/DDP cells revealed higher levels of HMGB1 in HeLa/DDP cells than in HeLa cells. Additionally, the half maximal inhibitory concentration $\left(\mathrm{IC}_{50}\right)$ value for cisplatin in $\mathrm{HeLa}$ /DDP cells was 5.3-fold that in HeLa cells. Analysis of the distribution of cellular components revealed that HMGB1 translocation from the nucleus to cytoplasm contributed to cisplatin resistance. This was further confirmed by demonstration that ethyl pyruvate treatment suppressed the cytoplasmic translocation of HMGB1, resulting in inhibition of HeLa cell proliferation. Furthermore, endogenous HMGB1 was inhibited with HMGB1-specific short hairpin (sh)RNA, and MTT assay results showed that interference with HMGB1 expression reduced cell viability and potentially reversed cisplatin resistance in HeLa cells. Transfection with HMGB1 shRNA was demonstrated to induce cell apoptosis in HeLa cells, as detected by FACS analysis. In addition, administration of recombinant HMGB1 protein in HeLa cells promoted cell autophagy, mediated by the phosphorylation of extracellular signal-regulated kinase 1/2. Thus, cytoplasmic HMGB1
\end{abstract}

Correspondence to: Miss. Jiyi Xia, School of Medical Information and Engineering, Southwest Medical University, 1 Xianglin Road, Luzhou, Sichuan 646000, P.R. China

E-mail: xiajiyi0615@163.com

*Contributed equally

Key words: cervical cancer, cisplatin, high mobility group box 1 , drug resistance translocation and HMGB1-induced cell autophagy are proposed to contribute to cisplatin resistance by inhibiting apoptosis of cervical cancer cells. HMGB1 could, therefore, represent a novel therapeutic target for, and a diagnostic marker of, chemotherapy resistant cervical cancers.

\section{Introduction}

Cervical cancer is the fourth most common malignancy in women globally $(1,2)$. Due to increased human papillomavirus infection rates, there were 450,000 new cases of cervical cancer worldwide and 20,000 women died from cervical cancer in $2014(3,4)$. In China, 131,500 new cases are diagnosed each year, accounting for $\sim 1 / 3$ of the world's new cases $(5,6)$. With improvements in diagnosis and treatment, the incidence and mortality of cervical cancer has significantly reduced, but has become more prevalent in younger age categories, with the number of patients $<35$ years old with cervical cancer significantly increased (7). The Pacific region has been particularly affected by increased rates of cervical cancer, with current age standardized incidence rates ranging from 8.2 to 50.7 per 100,000 women per year, and age standardized mortality rates ranging from 2.7 to 23.9 per 100,000 women per year (8).

Surgery or radiation therapy are the main treatments for cervical cancers, and traditional methods of treatment achieve higher cure rates for cervical cancer patients with early diagnosis (9). The overall 5-year survival rate is $\sim 70 \%$, and for patients without lymph node metastasis the 5-year survival rate is $80-90 \%$ (10). Surgical treatment is mainly used for patients with early-stage cervical cancer, but for patients with advanced cervical cancer, surgical treatment is usually combined with radiotherapy and chemotherapy (7). Chemotherapeutic treatment primarily comprises platinum based antineoplastic drugs, such as cisplatin and carboplatin, which are important anticancer drugs for gynecological malignancies $(10,11)$. Although cisplatin and carboplatin are both platinum-based, their ability to kill tumor cells and the side effects they elicit in normal tissues differ significantly (11). Thus, they cannot be substituted for each other in clinical applications. Currently, cisplatin is used more commonly than carboplatin, but cisplatin has greater side effects and increased toxicity, particularly renal toxicity (12). However, the greatest 
obstacle is resistance to chemotherapeutic drugs in patients with cervical cancer (13). Enhanced drug sensitivity and reversed drug resistance in cervical cancer cells is, therefore, an important area of research.

High mobility group box 1 (HMGB1) is a highly conserved chromosomal protein that acts as a DNA chaperone (14). It was first discovered in the calf thymus, and named according to its high electrophoretic mobility in polyacrylamide gels (15). HMGB1 is reported to influence transcription of cytokines, chemokines, and growth factors and works as a prototypical damage-associated molecular pattern in initiating and perpetuating inflammatory responses (16). It is involved in regulating multiple signaling pathways, including inflammation, genome stability, cell survival, metastasis, cell apoptosis and, in particular, cell autophagy (17). Previous studies have revealed a paradoxical dual effect of autophagy in cancer development and progression. Lipidated microtubule associated protein 1 light chain 3 (LC3)-II is a reliable marker for autophagy $(18,19)$. p62 is a selective autophagy substrate that recognizes ubiquitinated proteins to the autophagosome for degradation. HMGB1 was previously thought to be an oncogene, promoting cell growth and metastasis of cancers (15). However, the associations between HMGB1 expression and chemoresistance, and the underlying molecular mechanisms, were not entirely elucidated. Chemotherapy drugs including doxorubicin, cisplatin and methotrexate induce HMGB1 upregulation in human osteosarcoma cells, and knockdown of HMGB1 successfully restored chemosensitivity to osteosarcoma cells in vivo and in vitro (20).

Xie et al (21) also demonstrated that HMGB1 gene silencing can enhance the sensitivity of K562/A02 drug resistant leukemia cells to doxorubicin and reverse cell resistance to doxorubicin. However, the molecular mechanisms of HMGB1-associated drug resistance in cervical cancer cells remained unclear. In the present study, in order to explore the relationship between HMGB1 expression and chemotherapy drug resistance, the cisplatin-sensitive HeLa cells and cisplatin-resistant HeLa/DDP cells were used as models.

\section{Materials and methods}

Cell lines and reagents. Human cervical carcinoma HeLa cells and cisplatin-resistant HeLa cells (HeLa/DDP) were obtained from Shenglong Biological Corporation (Shanghai, China). Cells were maintained in Dulbecco's modified Eagle's medium (DMEM; Gibco; Thermo Fisher Scientific, Waltham, MA, USA) containing 10\% fetal bovine serum (Gibco; Thermo Fisher Scientific, Inc.), $100 \mu \mathrm{g} / \mathrm{ml}$ ampicillin and $50 \mu \mathrm{g} / \mathrm{ml}$ streptomycin at $37^{\circ} \mathrm{C}$ in a humidified atmosphere of $95 \%$ air and $5 \% \mathrm{CO}_{2}$. Cisplatin, ethyl pyruvate (EP) and MTT were obtained from Sigma Aldrich, Merck Millipore (Darmstadt, Germany). Recombinant human (rh) HMGB1/Fc was obtained from Sino Biological Inc. (Beijing, China; cat. no. 10326-H01H). The human HMGB1 short hairpin (sh) RNAs (cat. no. TG316576) and negative control (NC) shRNA (cat. no. TR30013) were obtained from OriGene Technologies, Inc. (Rockville, MD, USA).

Antibodies. $\beta$-actin antibody was purchased from TransBionovo Co., Ltd. (Beijing, China; cat. no. HC201;
1:1,000). Antibodies for caspase-3 (cat. no. 9662), cleaved (c)-caspase-3 (cat. no. 9661), poly ADP ribose polymerase (PARP; cat. no. 9542), c-PARP (cat. no. 9541), extracellular signal-regulated kinase 1/2 (ERK1/2; cat. no. 9102) and phosphorylated (p)-ERK1/2 (cat. no. 8544) were obtained from Cell Signaling Technology, Inc. (Danvers, MA, USA) and all diluted 1:1,000. $\beta$-Tubulin antibody (H-235), a rabbit polyclonal IgG provided at $200 \mu \mathrm{g} / \mathrm{ml}$ (cat. no. sc-9104; 1:1,000), was purchased from Santa Cruz Biotechnology, Inc. (Dallas, TX, USA). Anti-lamin B1 (cat. no. ab16048; 1:1,000) and anti-HMGB1 (cat. no. ab18256; 1:1,000), both rabbit polyclonal antibodies, were obtained from Abcam (Cambridge, UK). LC3B/MAP1LC3B antibody (cat. no. NB100-2220; 1:1,000) was purchased from Novus Biologicals, LLC (Littleton, CO, USA).

Cell transfection. HeLa, SiHa and HeLa/DDP cells were plated into 48 -well plates $\left(5 \times 10^{5}\right.$ cells/well) and incubated for $6 \mathrm{~h}$ prior to transfection with HMGB1 shRNA or NC shRNA using Lipofectamine 2000 transfection reagent (Invitrogen; Thermo Fisher Scientific Inc.) according to the manufacturer's protocol. The cells were then cultured for the indicated times before being subjected to MTT assays or western blotting analysis.

Annexin V-fluorescein isothiocyanate (FITC) dual staining analysis. Annexin V-FITC apoptosis detection kit (catalog no. ab14085) was obtained from Abcam; $2 \times 10^{5}$ cells were trypsinized into a single cell suspension. Resuspended cells were incubated with Annexin V-FITC $(0.1 \mu \mathrm{g} / \mu \mathrm{l})$ for $15 \mathrm{~min}$ in the dark on ice. Propidium iodide $(0.05 \mu \mathrm{g} / \mu \mathrm{l})$ was then added and used as a counterstain to discriminate between necrotic and apoptotic cells. Fluorescence-activated cell sorting (FACS) analysis was then performed and data was analyzed using FlowJo 10 software (FlowJo, LLC, Ashland, OR, USA).

Preparation of subcellular fractions and western blot analysis. HeLa cells and SiHa cells $\left(2 \times 10^{5}\right.$ cells/well) were plated into 48-well plates. Six hours later, the cells were treated with $10 \mu \mathrm{g} / \mathrm{ml}$ of cisplatin for 24 and $48 \mathrm{~h}$, respectively. Cytosolic extracts and nuclear extracts were prepared using a Nuclear and Cytoplasmic Protein Extraction kit (catalog no. P0028; Beyotime, Institute of Biotechnology, Shanghai, China) according to the manufacturer's protocols. Protein concentrations of the extracts were measured by bicinchoninic acid assay (Pierce; Thermo Fisher Scientific, Inc.). Equal amounts $(15 \mu \mathrm{g})$ of the proteins were loaded and subjected to $10 \%$ SDS-PAGE and transferred onto nitrocellulose membranes. The membrane was blocked with $5 \%$ bovine serum albumin (Sigma-Aldrich; Merck Millipore) in Tris-buffered saline-0.1\% Tween-20 (TBST) buffer for $40 \mathrm{~min}$ at room temperature. Membranes were then incubated with the indicated primary antibodies overnight at $4^{\circ} \mathrm{C}$ and secondary antibodies for $40 \mathrm{~min}$ at room temperature. The membranes were washed three times in each step for 5 min with TBST buffer. The bands were then visualized using Pierce ECL Western Blotting Substrate (Thermo Fisher Scientific, Inc.). The bands were captured and analyzed with ImageJ software (National Institutes of Health, Bethesda, MD, USA) and the expression of HMGB1 was normalized to $\beta$-actin. 


\section{A}

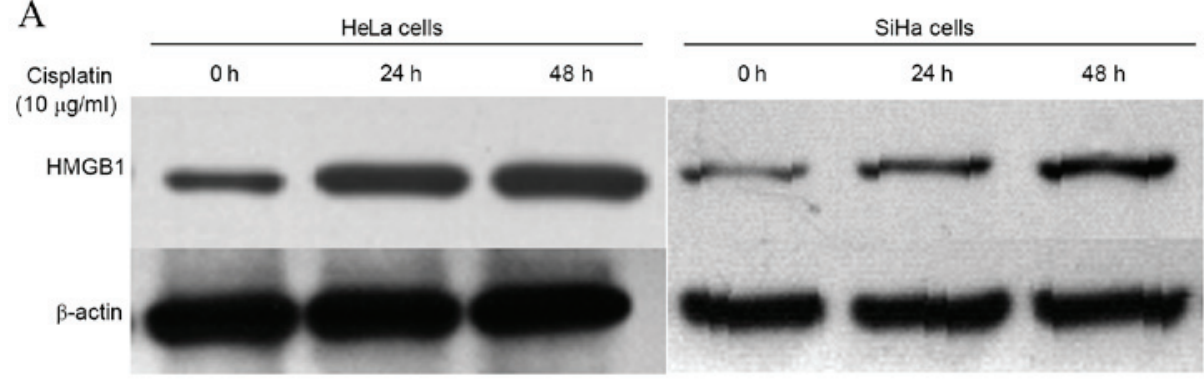

B
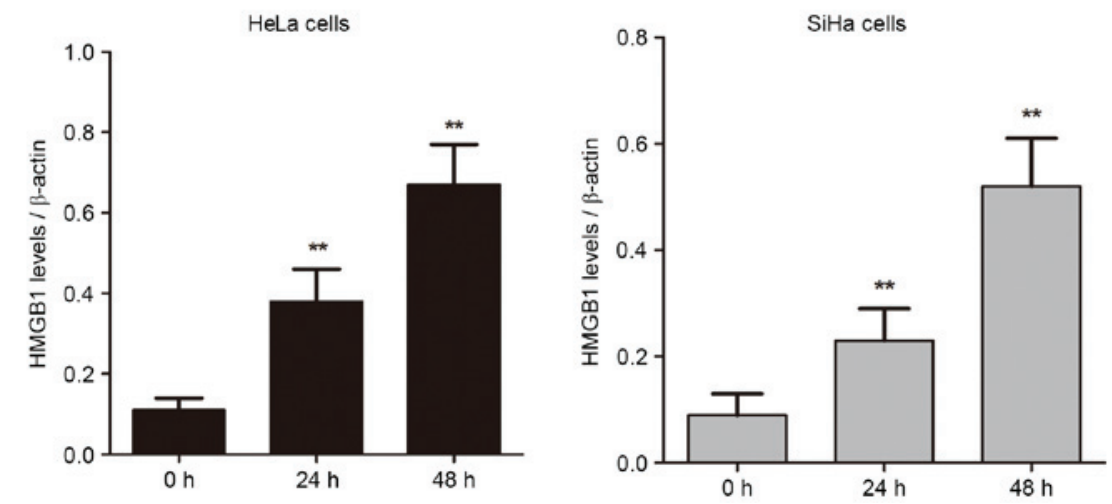

Figure 1. Cisplatin treatment increases the expression levels of HMGB1 in a time-dependent manner. Protein expression levels of HMGB1 in cisplatin-treated (A) HeLa and (B) SiHa cells were examined by western blotting and quantified relative to $\beta$-actin. ${ }^{* *} \mathrm{P}<0.01 \mathrm{vs}$. 0 h. HMGB1, high mobility group box 1 protein.

MTT assay. The tumor inhibition rates of cisplatin and EP on HeLa cells and HeLa/DPP cells were detected by MTT assay. The cervical cancer cells were plated into 96-well plates $\left(2 \times 10^{4}\right.$ cells/well) and cultured for $6 \mathrm{~h}$ in DMEM. They were subsequently treated with the $10 \mu \mathrm{g} / \mathrm{ml}$ cisplatin and stimulated for 24, 48 and $72 \mathrm{~h}$, respectively. MTT $(5 \mathrm{mg} / \mathrm{ml})$ was added into the medium and $150 \mu 1$ DMSO was used to dissolve the formazan crystals. The 96 -well plates were read on a microplate reader at a test wavelength of $490 \mathrm{~nm}\left(\mathrm{~A}_{490}\right)$.

The growth inhibition rate was calculated as follows: growth inhibition rate $(\%)=\left(\right.$ average $\mathrm{A}_{490}$ of the control group - average $\mathrm{A}_{490}$ value of the experimental group)/average $\mathrm{A}_{490}$ value of the control group x $100 \%$.

Statistical analysis. All of the data were analyzed by SPSS 19.0 software (SPSS Inc., Chicago, IL, USA) and are presented as the mean \pm standard deviations. $\mathrm{P}<0.05$ was considered to indicate a statistically significant difference.

\section{Results}

Cisplatin treatment increases the protein expression levels of HMGB1 in a time-dependent manner. HMGB1 is a nucleoprotein that is associated with cancer progression (22-24). To examine whether HMGB1 is involved in drug resistance in cervical cancer cells, two cisplatin-sensitive cell lines, HeLa and $\mathrm{SiHa}$, were treated with $10 \mu \mathrm{g} / \mathrm{ml}$ of cisplatin for 24 and $48 \mathrm{~h}$. Expression of HMGB1 was significantly increased compared with untreated cells in at 24 and $48 \mathrm{~h}$ in both $\mathrm{HeLa}$ $(\mathrm{P}=0.032$ and $\mathrm{P}=0.014$, respectively; Fig. 1A) and SiHa cells $(\mathrm{P}=0.038$ and $\mathrm{P}=0.011$, respectively; Fig. 1B). These findings suggest that cisplatin-induced HMGB1 expression in cervical cancers may be involved in drug resistance.
Higher levels of HMGB1 are detected in a cisplatin-resistant subline of cervical cancer cells. The cervical cancer cell line HeLa and its cisplatin-resistant subline, HeLa/DDP were used as models. MTT assays were performed to examine the levels of cisplatin resistance in these cell lines. The cisplatin-sensitive HeLa and cisplatin-resistant HeLa/DDP cells were treated with increasing concentrations of cisplatin for $48 \mathrm{~h}$, and half maximal inhibitory concentration $\left(\mathrm{IC}_{50}\right)$ values were calculated as 4.27 and $22.70 \mu \mathrm{g} / \mathrm{ml}$, respectively (Fig. 2A). The $\mathrm{IC}_{50}$ value in the HeLa/DDP cell line was 5.3-fold that in the HeLa cell line, confirming that HeLa/DDP had higher resistance to cisplatin than HeLa cells (Fig. 2A).

HMGB1 protein expression levels were detected by western blotting analysis in both HeLa and HeLa/DDP cells. HeLa/DDP cells exhibited higher protein expression levels of HMGB1 than cisplatin-sensitive HeLa cells (Fig. 2B), which suggested that increased HMGB1 expression was associated with cisplatin drug resistance in HeLa cervical cancer cells.

Association of cytoplasmic location of HMGBI and cisplatin resistance in cervical cancer cells. Under normal conditions, HMGB1 is a non-histone nuclear protein $(25,26)$. To establish whether the location of HMGB1 was altered in drug resistant cancer cells, protein in the cytoplasm and nucleus was extracted from cisplatin-treated HeLa cells, and HMGB1 expression was detected in cytoplasmic and nuclear fractions by western blotting (Fig. 3). Protein expression levels of HMGB1 in HeLa cells increased in a time dependent manner over the course of $48 \mathrm{~h}$ (Fig. 3A). In addition, cytoplasmic HMGB1 increased with time when treated with cisplatin (Fig. 3B), while the levels of HMGB1 in the nucleus decreased (Fig. 3C). This suggests that HMGB1 translocation from the nucleus to cytoplasm may be associated with cisplatin resistance. 
$\mathbf{A}$

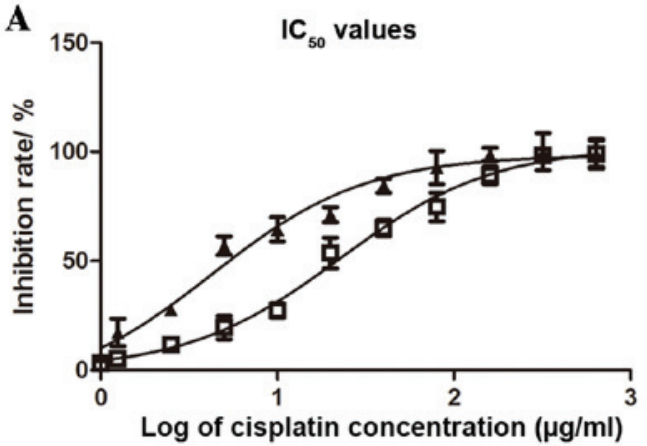

B

\begin{tabular}{|c|c|c|}
\hline & Hela & Hela/DDP \\
\hline IC50 & 4.269 & 22.70 \\
\hline
\end{tabular}

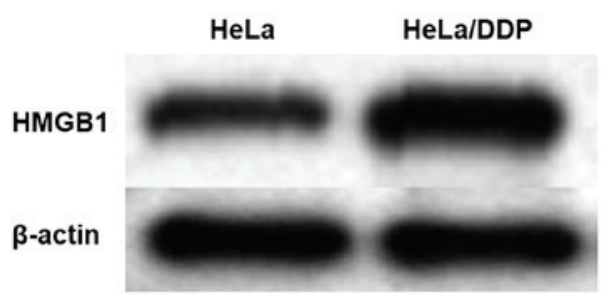

Figure 2. Higher levels of HMGB1 are detected in a cisplatin-resistant subline of cervical cancer cells. (A) Growth inhibition rate of HeLa and HeLa/DPP cells in increasing concentrations was determined by MTT assay, and the $\mathrm{IC}_{50}$ calculated. (B) HMGB1 protein expression levels were determined by western blot in $\mathrm{HeLa}$ and $\mathrm{HeLa} / \mathrm{DPP}$ cells treated with $10 \mu \mathrm{l} / \mathrm{ml}$ cisplatin for $48 \mathrm{~h}$. $\beta$-actin was used as an internal control. HMGB1, high mobility group box 1 protein. $\mathrm{IC}_{50}$, half maximal inhibitory concentration.

A Cisplatin $(10 \mu \mathrm{g} / \mathrm{ml})$

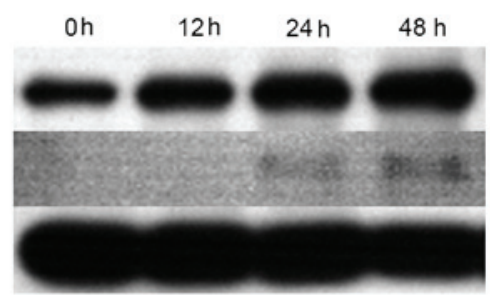

B

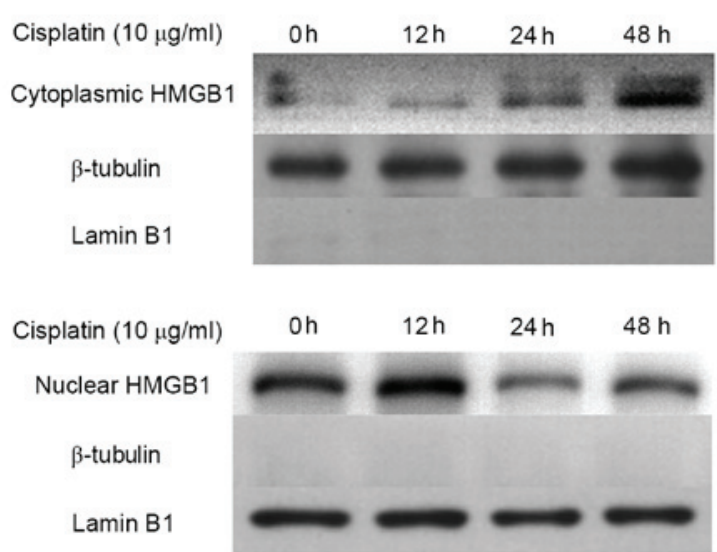

Figure 3. Cytoplasmic location of HMGB1 contributes to cisplatin resistance in cervical cancer cells. HeLa cells were treated with $10 \mu \mathrm{g} / \mathrm{ml}$ of cisplatin for the indicated times, and the expression and cellular location of HMGB1 was detected by western blotting analysis. (A) Protein expression levels of HMGB1 and the extra-HMGB1 levels were detected by western blotting in the supernatant with $\beta$-actin as an internal control. (B) Cytoplasmic HMGB1 levels were detected in cytoplasmic fractions with $\beta$-tubulin used as a cytoplasmic marker. (C) HMGB1 protein levels were detected in nuclear fractions, with lamin B1 used as a nuclear marker. HMGB1, high mobility group box 1 protein; extra-HMGB1, extracellular HMGB1.

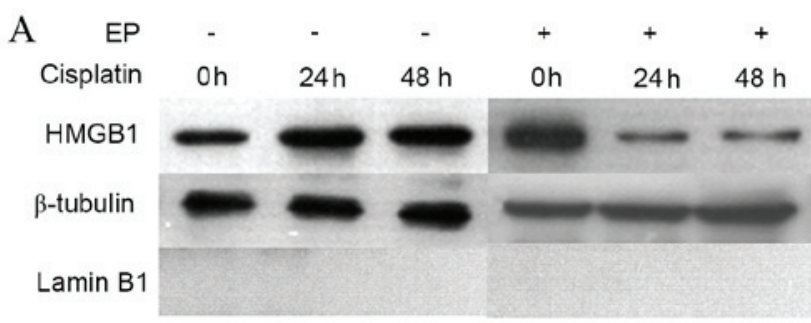

B
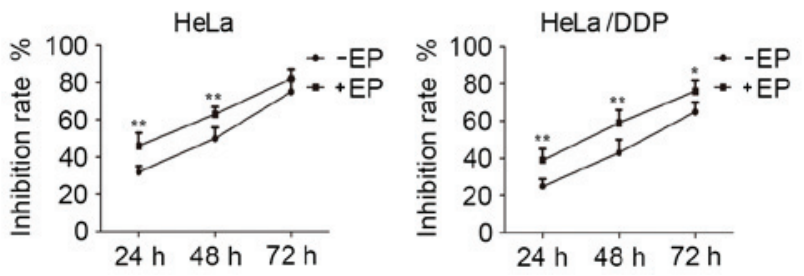

Figure 4. EP inhibits the proliferation of cervical cancer cells. (A) HeLa cells were incubated with or without $10 \mathrm{mM}$ EP for $5 \mathrm{~h}$, then incubated in fresh medium with $10 \mu \mathrm{g} / \mathrm{ml}$ cisplatin for a further $48 \mathrm{~h}$. Cytoplasmic fractions were isolated from samples at 0,24 and $48 \mathrm{~h}$, and HMGB1 protein expression levels were detected by western blot with $\beta$-tubulin as a cytoplasmic marker and lamin B1 as a nuclear marker. (B) Growth inhibition rates were assessed by MTT assay in HeLa and HeLa/DDP cells incubated with/without $10 \mathrm{mM}$ EP for 3 h. ${ }^{*} \mathrm{P}<0.05$ and ${ }^{* *} \mathrm{P}<0.01$ vs. EP untreated cells at the same time-point EP, ethyl pyruvate; HMGB1, high mobility group box 1 protein.

Ethyl pyruvate (EP) inhibits the cytoplasmic translocation of $H M G B 1$ and suppresses the proliferation of cervical cancer cells. To further investigate the involvement of HMGB1 translocation in drug resistance a pharmacological inhibitor of HMGB1 cytoplasmic translocation, EP, was used to treat HeLa cells. EP treatment alongside cisplatin reduced the levels of cytoplasmic HMGB1 in cisplatin-treated HeLa cells at 24 and $48 \mathrm{~h}$ (Fig. 4A). Notably, the growth inhibition rate in EP-treated HeLa and HeLa/DDP cells was significantly increased compared with cells without EP treatment (Fig. 4B), suggesting EP may significantly inhibit translocation of HMGB1 into the cytoplasm and suppressed the proliferation of cervical cancer cells.

Interference with endogenous $H M G B 1$ expression inhibits the proliferation of HeLa cells exposed to cisplatin. RNA interference technology was used to interfere with the expression of endogenous HMGB1. As demonstrated in Fig. 5A, the expression of HMGB1 was reduced in both the cytoplasm and nucleus of HeLa cells transfected with HMGB1 shRNA compared with NC shRNA. MTT assays were then used to detect the effects of interference with HMGB1 on the drug resistance of cisplatin in HeLa cells. As demonstrated in Fig. 5B, the growth inhibition rate was significantly higher in HMGB1 shRNA transfected, cisplatin-treated HeLa cells, compared with NC shRNA transfected, cisplatin-treated HeLa cells at 48 and $72 \mathrm{~h}(\mathrm{P}=0.009$ and $\mathrm{P}=0.009$; Fig. 5B, HeLa cells). This effect was also observed in HeLa/DPP cells at 48 and $72 \mathrm{~h}$ ( $\mathrm{P}=0.009$ and $\mathrm{P}=0.007$; Fig. 5B; HeLa/DPP cells). Therefore, HeLa and HeLa/DPP cells transfected with HMGB1 shRNA demonstrated reduced proliferation.

Transfection with HMGBI in HeLa cells induces cell apoptosis in cervical cancer cells. The cell apoptosis rate was determined by FACS analysis in HeLa cells transfected with 
A

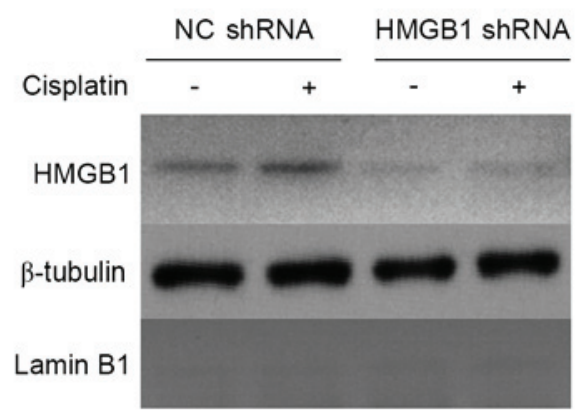

Nucleus

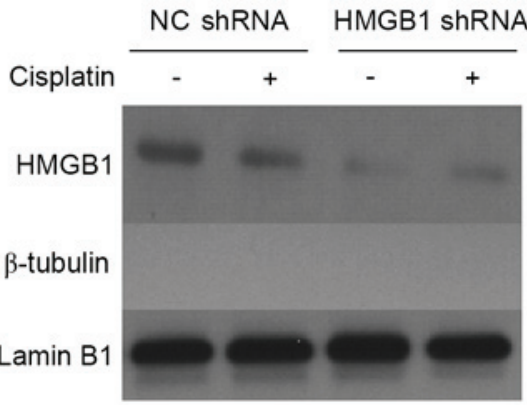

B

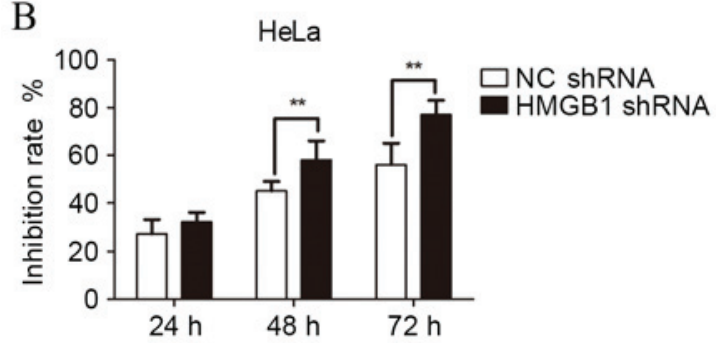

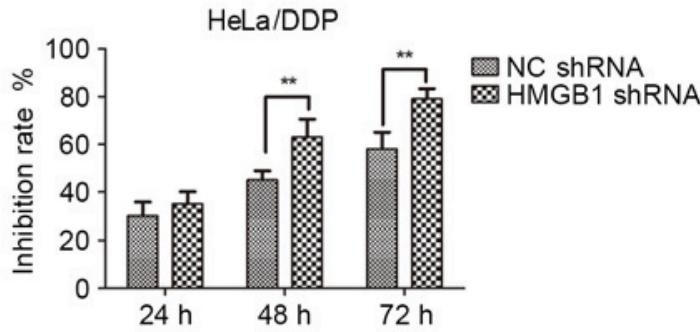

Figure 5. Interference with endogenous HMGB1 expression increases the sensitivity of HeLa cells to cisplatin. (A) HMGB1 protein expression levels were detected by western blotting in cytoplasmic and nuclear extracts from HeLa cells transfected with HMGB1 shRNA or NC shRNA, and incubated with/without $10 \mu \mathrm{g} / \mathrm{ml}$ cisplatin for $24 \mathrm{~h}$. $\beta$-Tubulin was used as a cytoplasmic marker and lamin B1 as a nuclear marker. (B) Growth inhibition rates were determined by MTT assay in HeLa and HeLa/DDP cells transfected with HMGB1 shRNA or NC shRNA, and incubated with $10 \mu \mathrm{g} / \mathrm{ml}$ cisplatin for 24,48 and $72 \mathrm{~h}$. ${ }^{* *} \mathrm{P}<0.01$, with comparisons indicated by brackets. HMGB1, high mobility group box 1 protein; ctrl, control; shRNA, short hairpin RNA; NC, negative control.

A

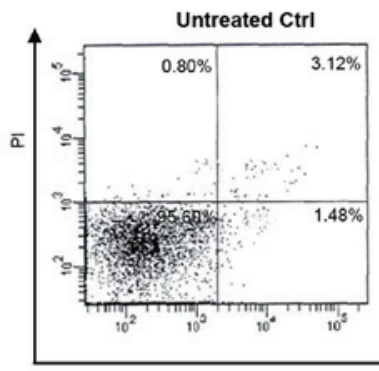

B

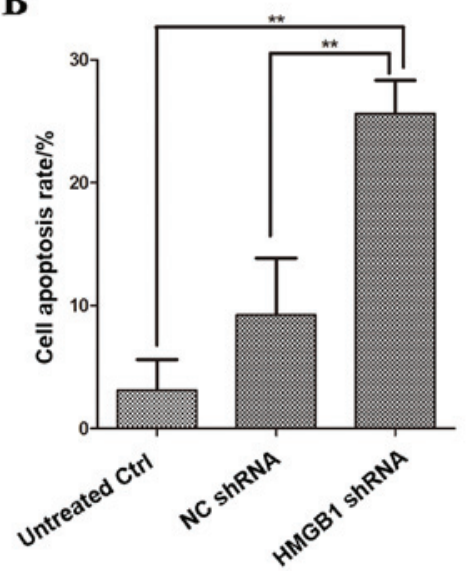

NC ShRNA

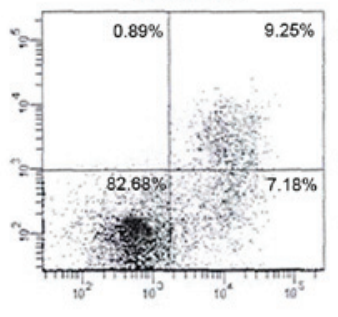

C

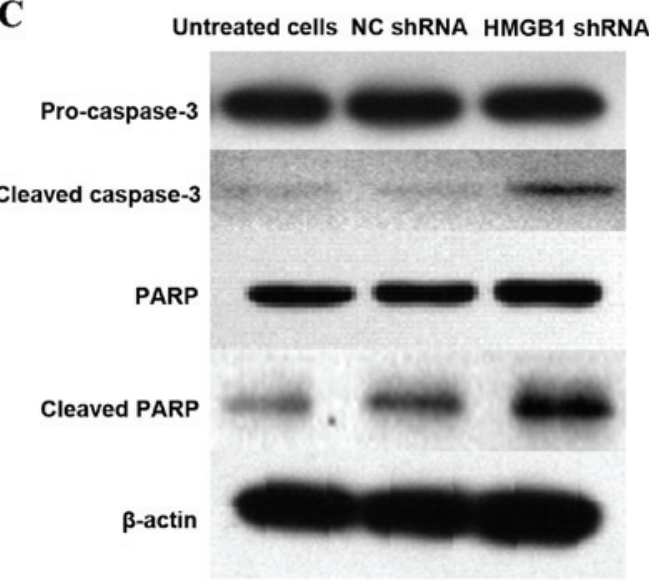

Figure 6. Transfection with HMGB1 induces cell apoptosis in HeLa cells. HeLa cells were transfected with HMGB1 shRNA or NC shRNA and treated with $10 \mu \mathrm{g} / \mathrm{ml}$ of cisplatin for $48 \mathrm{~h}$. (A) Cell apoptosis was detected by an Annexin V-PI dual staining analysis, ${ }^{* *} \mathrm{P}<0.01$ (B). Expression levels of apoptosis-related proteins were detected by western blot analysis of whole cell lysates. $\beta$-actin was used as an internal control (C). HMGB1, high mobility group box protein 1 ; shRNA, short hairpin RNA; NC, negative control; ctrl, control; PI, propidium iodide; PARP, poly ADP ribose polymerase.

HMGB1 shRNA and NC shRNA, and then treated with $10 \mu \mathrm{g} / \mathrm{ml}$ cisplatin for $48 \mathrm{~h}$. FACS analysis revealed that the apoptosis rate in HMGB1 shRNA transfected HeLa cells was significantly greater than in NC shRNA transfected HeLa cells 
A

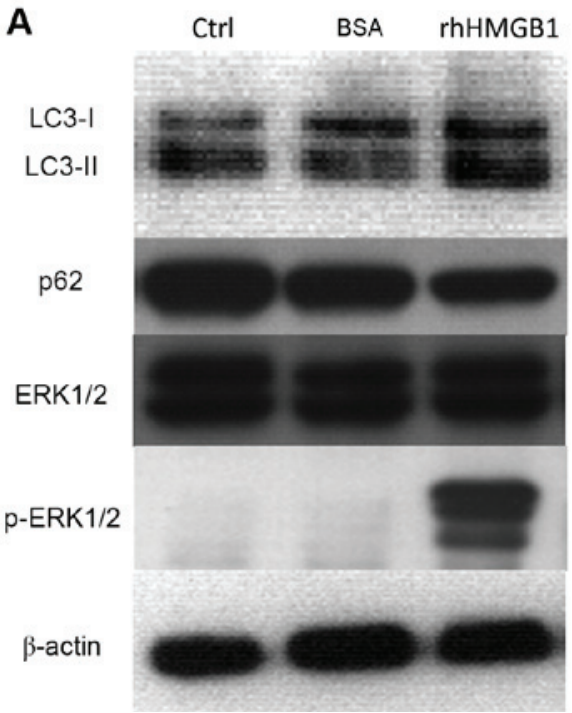

B

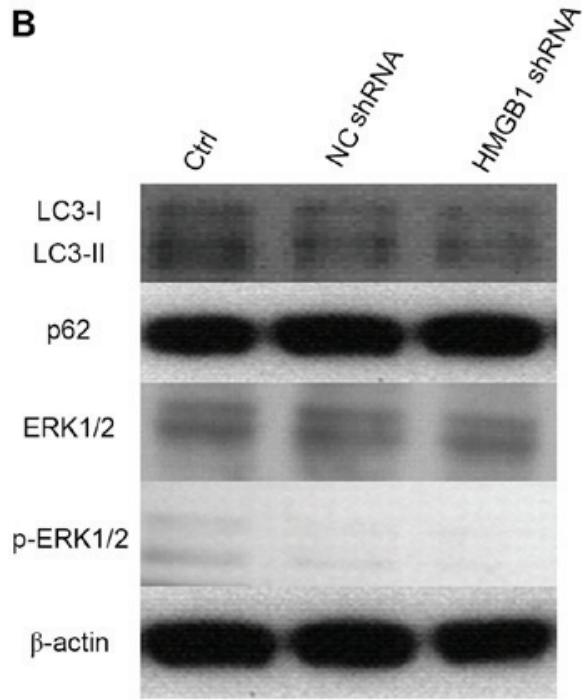

Figure 7. Cell autophagy induced by HMGB1 treatment in HeLa cells is mediated by the ERK1/2 pathway. Western blot analysis of LC3-I, LC3-II, p62, ERK1/2 and p-ERK1/2 protein levels was performed in (A) $24 \mathrm{~h}$ serum-starved HeLa cells, treated with $100 \mu \mathrm{g} / \mathrm{ml} \mathrm{rhHMGB} 1 \mathrm{or} 100 \mu \mathrm{g} / \mathrm{ml} \mathrm{BSA}$ for $48 \mathrm{~h}$, and (B) HeLa cells transfected with NC shRNA and HMGB1 shRNA. $\beta$-actin was used as a loading control. HMGB1, high mobility group box protein 1; ERK1/2, extracellular signal-related kinases 1 and 2; LC3, microtubule associated protein 1 light chain 3; shRNA, short hairpin RNA; NC, negative control; p62, nucleoporin p62; p, phosphorylated; BSA, bovine serum albumin; rh, recombinant human.

$(\mathrm{P}=0.003$; Fig. 6A). In addition, the presence of caspase-3, the executor of cell apoptosis, and its substrate PARP, were detected by western blotting analysis in cisplatin-treated HMGB1 shRNA/NC shRNA transfected HeLa cells, and in untreated/untransfected cells (Fig. 6B). The levels of cleaved, and therefore activated, caspase-3 and PARP were higher in HMGB1 shRNA transfected HeLa cells than in untreated/untransfected cells and cisplatin-treated NC shRNA cells (Fig. 6B).

Cell autophagy induced by extracellular HMGB1 treatment is mediated by the ERK1/2 pathway. Compared with FBS-treated cells, the levels of LC3-II in HeLa cells treated with rhHMGB1 were increased, while nucleoporin p62 levels were reduced (Fig. 7A). This suggests that administration of rhHMGB1 resulted in degradation of p62 and induction of cell autophagy. Furthermore, treatment with rhHMGB1 increased the phosphorylation of ERK1/2 (Fig. 7A), which results in activation of the MEK/ERK1/2 signaling pathway. By contrast, interference with endogenous expression of HMGB1 using HMGB1 shRNA, did not affect levels of p-ERK1/2, LC3-II and p62 compared with NC shRNA transfected cells (Fig. 7B).

\section{Discussion}

Previous studies into cervical cancer treatments have focused on prevention methods, including HPV DNA testing, HPV vaccination and Pap smear issues $(27,28)$. However, resistance to chemotherapeutic drugs remains a major obstacle in the treatment of cervical cancer. Investigations into the mechanisms of drug resistance in human cervical cancer cell lines, and methods of reversing resistance, have been explored by numerous researchers, but the mechanisms are yet to be clearly elucidated.

In the present study, it was revealed that levels of HMGB1 in cervical cancer cells significantly increased as a result of cisplatin treatment, in a time-dependent manner. Protein expression levels of HMGB1 were also demonstrated to be significantly higher in cisplatin-resistant HeLa/DDP than in cisplatin-sensitive HeLa cells, suggesting that increased levels of HMGB1 contribute to cisplatin resistance in cervical cancer cells. Furthermore, HMGB1 levels were upregulated as the cisplatin treatment time increased. Clinical samples of cervical cancers will therefore be collected in a future study to determine whether HMGB1 levels in the serum or tissues could be used as a diagnostic marker for cervical cancers.

Induction of autophagy has been observed to contribute to drug resistance in tumor cells (20). Chen et al (29) reported that abrogation of autophagy could restore lapatinib sensitivity to ErbB2 receptor (HER2) tyrosine kinase-positive breast cancers. In human esophageal cancers with acquired resistance to cisplatin, induction of autophagy has been demonstrated to be accompanied by the suppression of mechanistic target of rapamycin complex 1 (mTORC1) activity, which promotes cell autophagy, while inhibition of autophagy re-sensitizes cancer cells to cisplatin (30). In the present study, it was demonstrated that cisplatin treatment induces HMGB1 expression in HeLa cells, and that increased HMGB1 is associated with increased cisplatin resistance and results in induction of autophagy. In addition, inhibition of HMGB1 expression promotes apoptosis in cisplatin-treated HeLa cells. These findings demonstrate that HMGB1 may be an important factor in the development of chemoresistance and may represent a new target for the treatment of human cervical cancers.

\section{Acknowledgements}

The present study was supported by the Sichuan Provincial Department of Science and Technology (grant no. 14JC0135) and Luzhou Municipal Science and Technology Bureau (grant no. 2014-S-35). 


\section{References}

1. Boutas I, Sofoudis C, Kalampokas E, Anastasopoulos C, Kalampokas T and Salakos N: Fertility preservation in women with early stage cervical cancer. Review of the literature. Eur J Gynaecol Oncol 35: 373-377, 2014.

2. Arimoto T, Kawana K, Adachi K, Ikeda Y, Nagasaka K, Tsuruga T, Yamashita A, Oda K, Ishikawa M, Kasamatsu T, et al: Minimization of curative surgery for treatment of early cervical cancer: A review. Jpn J Clin Oncol 45: 611-616, 2015.

3. Huang QT, Zhong M, Gao YF, Huang LP, Huang Q, Wang W, Wang ZJ and Yu YH: Can HPV vaccine have other health benefits more than cancer prevention? A systematic review of association between cervical HPV infection and preterm birth J Clin Virol 61: 321-328, 2014.

4. Mann L, Foley KL, Tanner AE, Sun CJ and Rhodes SD: Increasing cervical cancer screening among us hispanics/latinas: A qualitative systematic review. J Cancer Educ 30: 374-387, 2015

5. Jiang J, Pang H, Liu B, Nasca PC, Zhang B, Wu Y, Han W, Gates M, Lu T, Zou X, et al: Effects of active, passive, and combined smoking on cervical cancer mortality: A nationwide proportional mortality study in Chinese urban women. Cancer Causes Control 26: 983-991, 2015.

6. Maguire R, Kotronoulas G, Simpson M and Paterson C: A systematic review of the supportive care needs of women living with and beyond cervical cancer. Gynecol Oncol 136: 478-490, 2015.

7. Li H, Wu X and Cheng X: Advances in diagnosis and treatment of metastatic cervical cancer. J Gynecol Oncol 27: e43, 2016.

8. Obel J, Souares Y, Hoy D, Baravilala W, Garland SM, Kjaer SK and Roth A: A systematic review of cervical cancer incidence and mortality in the Pacific Region. Asian Pac J Cancer Prev 15 9433-9437, 2014

9. Gadducci A, Tana R, Cosio S and Cionini L: Treatment options in recurrent cervical cancer (Review). Oncol Lett 1: 3-11, 2010.

10. Smits RM, Zusterzeel PL and Bekkers RL: Pretreatment retroperitoneal para-aortic lymph node staging in advanced cervical cancer: A review. Int J Gynecol Cancer 24: 973-983, 2014.

11. Lorusso D, Petrelli F, Coinu A, Raspagliesi F and Barni S: A systematic review comparing cisplatin and carboplatin plus paclitaxel-based chemotherapy for recurrent or metastatic cervical cancer. Gynecol Oncol 133: 117-123, 2014.

12. Turan T, Yildirim BA, Tulunay G, Boran N, Yildiz F and Köse MF: Experience in stage IB2 cervical cancer and review of treatment. J Turk Ger Gynecol Assoc 11: 27-37, 2010.

13. Sun R, Jiang B, Qi H, Zhang X, Yang J, Duan J, Li Y and Li G: SOX4 contributes to the progression of cervical cancer and the resistance to the chemotherapeutic drug through ABCG2. Cell Death Dis 6: e1990, 2015.

14. Andersson U, Erlandsson-Harris H, Yang H and Tracey KJ: HMGB1 as a DNA-binding cytokine. J Leukoc Biol 72 : 1084-1091, 2002.

15. Kang R, Zhang Q, Zeh HJ III, Lotze MT and Tang D: HMGB1 in cancer: Good, bad, or both? Clin Cancer Res 19: 4046-4057, 2013

16. Lolmede K, Campana L, Vezzoli M, Bosurgi L, Tonlorenzi R, Clementi E, Bianchi ME, Cossu G, Manfredi AA, Brunelli S and Rovere-Querini P: Inflammatory and alternatively activated human macrophages attract vessel-associated stem cells, relying on separate HMGB1- and MMP-9-dependent pathways. J Leukoc Biol 85: 779-787, 2009.
17. Szénási T, Kénesi E, Nagy A, Molnár A, Bálint BL, Zvara Á, Csabai Z, Deák F, Boros Oláh B, Mátés L, et al: Hmgb1 can facilitate activation of the matrilin-1 gene promoter by Sox 9 and L-Sox 5/Sox6 in early steps of chondrogenesis. Biochim Biophys Acta 1829: 1075-1091, 2013.

18. Galluzzi L, Pietrocola F, Bravo-San Pedro JM, Amaravadi RK, Baehrecke EH, Cecconi F, Codogno P, Debnath J, Gewirtz DA, Karantza V, et al: Autophagy in malignant transformation and cancer progression. EMBO J 34: 856-880, 2015.

19. Berardi DE, Campodónico PB, Díaz Bessone MI, Urtreger AJ and Todaro LB: Autophagy: Friend or foe in breast cancer development, progression and treatment. Int J Breast Cancer 2011: 595092, 2011.

20. Huang J, Ni J, Liu K, Yu Y, Xie M, Kang R, Vernon P, Cao L and Tang D: HMGB1 promotes drug resistance in osteosarcoma. Cancer Res 72: 230-238, 2012.

21. Xie M, Kang R, Yu Y, Zhu S, He YL, Xu WQ, Tang DL and Cao LZ: Enhancive effect of HMGB1 gene silence on adriamycin-induced apoptosis in K562/A02 drug resistance leukemia cells. Zhonghua Xue Ye Xue Za Zhi 29: 549-552, 2008 (In Chinese).

22. Suren D, Yıldırım M, Demirpençe Ö, Kaya V, Alikanoğlu AS, Bülbüller N, Yildız M and Sezer C: The role of high mobility group box 1 (HMGB1) in colorectal cancer. Med Sci Monit 20: 530-537, 2014

23. Gnanasekar M, Kalyanasundaram R, Zheng G, Chen A, Bosland MC and Kajdacsy-Balla A: HMGB1: A Promising therapeutic target for prostate cancer. Prostate Cancer 2013: 157103, 2013.

24. Zhang X, Wang $\mathrm{H}$ and Wang J: Expression of HMGB1 and $\mathrm{NF}-\kappa \mathrm{B}$ p65 and its significance in non-small cell lung cancer. Contemp Oncol (Pozn) 17: 350-355, 2013

25. Ohmori H, Luo Y and Kuniyasu H: Non-histone nuclear factor HMGB1 as a therapeutic target in colorectal cancer. Expert Opin Ther Targets 15: 183-193, 2011.

26. Lee H, Shin N, Song M, Kang UB, Yeom J, Lee C, Ahn YH, Yoo JS, Paik YK and Kim H: Analysis of nuclear high mobility group box 1 (HMGB1)-binding proteins in colon cancer cells: Clustering with proteins involved in secretion and extranuclear function. J Proteome Res 9: 4661-4670, 2010

27. Bukowska-Durawa A and Luszczynska A: Cervical cancer screening and psychosocial barriers perceived by patients. A systematic review. Contemp Oncol (Pozn) 18: 153-159, 2014.

28. Kavallaris A, Zygouris D, Dafopoulos A, Kalogiannidis I and Terzakis E: Nerve sparing radical hysterectomy in early stage cervical cancer. Latest developments and review of the literature. Eur J Gynaecol Oncol 36: 5-9, 2015.

29. Chen S, Li X, Feng J, Chang Y, Wang Z and Wen A: Autophagy facilitates the Lapatinib resistance of HER2 positive breast cancer cells. Med Hypotheses 77: 206-208, 2011.

30. Yu L, Gu C, Zhong D, Shi L, Kong Y, Zhou Z and Liu S: Induction of autophagy counteracts the anticancer effect of cisplatin in human esophageal cancer cells with acquired drug resistance. Cancer Lett 355: 34-45, 2014. 